\title{
Cylindrocarpon destructans Causador do "Pé-Preto" da Videira no Rio Grande do Sul
}

\author{
Lucas da R. Garridoํㅜ, Olavo R. Sônego ${ }^{1}$ \& Arailde F. Urben²
}

${ }^{1}$ Laboratório de Fitopatologia, Embrapa Uva e Vinho, Cx. Postal 130, CEP 95700-000, Bento Gonçalves, RS; ${ }^{2}$ Laboratório de Micologia, Prédio de Quarentena Vegetal. Embrapa Recursos Genéticos e Biotecnologia, Cx. Postal 02372, CEP 70770-900,

Brasília, DF, e-mail: garrido@cnpuv.embrapa.br

(Aceito para publicação em 12/04/2004)

Autor para correspondência: Lucas da R. Garrido

GARRIDO, L.G., SÔNEGO, O.R. \& URBEN, A.F. Cylindrocarpon destructans causador do "pé-preto” da videira no Rio Grande do Sul. Fitopatologia Brasileira 29:548-550. 2004.

\section{RESUMO}

Desde 1999 tem sido observada a morte de videiras (Vitis labrusca) americanas no Rio Grande do Sul. A doença é caracterizada pelo apodrecimento do colo da planta e do sistema radicular, seguindose o murchamento da parte áerea e, conseqüentemente, a morte da planta. Com base no isolamento, na comprovação da patogenicidade e nas características morfológicas, identificou-se o agente causal como sendo Cylindrocarpon destructans. Este é o primeiro relato no Brasil do “pé-preto" da videira.

Palavras-chave adicionais: black foot, declínio de videiras, Vitis labrusca, fungos.

\section{ABSTRACT}

Cylindrocarpon destructans causal agent of grapevine blackfoot in Rio Grande do Sul

Since 1999, a death of the American grapevine (Vitis labrusca) has been noted in the state of Rio G rande do Sul, Brazil. The disease is characterized by stem and root rotting followed by wilt and plant death. Based on isolation, pathogenicity confirmation and morphological characteristics, Cylindrocarpon destructans was identified as the causal agent of the disease. This is the first report of black foot on grapevine in Brazil.
No ano de 2001, em 15 municípios da Serra Gaúcha foram observadas diversas plantas de uvas americanas (Vitis labrusca L.) das variedades Bordô, Niágara e Concord com menos de cinco anos de idade, apresentando escurecimento na região do colo, redução do vigor, secamento da parte aérea, declínio e morte. Desde 1999, já haviam sido constatados, em algumas plantas de videira da região, estes mesmos sintomas. Por outro lado, o histórico de ocorrência de outros patógenos de solo na região vitivinícola da Serra Gaúcha como Fusarium oxysporum Schl. f.sp. herbemontis Tocchetto, Armilaria mellea (Vahl.:Fr.) Kummer e Rosellinia necatrix Prill., tem sido bastante comum, principalmente do primeiro. Uma doença semelhante, ocorrendo em videiras, foi relatada em outros países da Europa e América do Norte, com o nome "black-foot", causada por Cylindrocarpon sp. (Scheck et al., 1998; Rego et al., 2000).

O declínio de videiras jovens foi observado em Portugal no início da década de 90, causado por Cylindrocarpon destructans (Zinssm.) Scholten (Rego et al., 2000). Em 1975, foi relatado na Itália, a morte de plantas causada por $C$. obtusisporum (Cook \& Harkn.) Wollenweb (Grasso \& Magnano di San Lio, 1975). Nos Estados Unidos, de amostras de plantas de videiras novas com sintomas de declínio, também foram isolados C. obtusisporum, além de Phaeoacremonium inflatipes W. Gams et al., P. chlamydosporum W. Gams, Crous, M.J. Wingf. \& L. Mugnai e P. aleophylum W. Gams et al. (Scheck et al., 1998).
Na Espanha, em 140 vinhedos, foram identificadas as espécies de fungos presentes nas plantas que apresentavam sintomas de declínio. As espécies encontradas foram: Botryosphaeria obtusa (Schwein.) Shoemaker (65,4\%), Phaeoacremonium aleophylum (26,4\%), Cylindrocarpon spp. (20\%), P. chlamydospora (18,6\%) e Fomitiporia punctata (Fr.) Murril (15\%) e, ocorrendo em menor freqüência Botryosphaeria dothidea (Moug.:Fr.) Ces. \& De Not. (6,4\%), Eutypa lata (Pers.:Fr.) Tul. \& C. Tul.(2,1\%) e Stereum hirsutum (Willd.) Pers. (1,4\%) (Armengol et al., 2001).

Na Grécia, no período de 1998 a 2001, amostras de diferentes cultivares enxertadas em vários porta-enxertos apresentaram declínio alguns meses ou anos depois de plantadas. Os fungos isolados foram: P. chlamydospora, F. punctata, S. hirsutum, Phaeoacremonium sp., Cylindrocarpon sp. e Botryosphaeria sp. (Rumbos \& Rumbou, 2001).

O fungo Cylindrocarpon spp. tem uma larga distribuição geográfica, ocorrendo em todos os continentes, podendo ser encontrado desde as florestas tropicais até em solo da tundra Ártica. É encontrado desde as camadas mais superficiais do solo até vários centímetros de profundidade, podendo crescer em baixas concentrações de oxigênio. Considerado como colonizador pioneiro de raízes jovens devido à habilidade competitiva, rápida germinação dos esporos e rápido crescimento micelial, além de certas 
Cylindrocarpon destructans causador do “pé-preto” da videira no...

características fisiológicas, como a utilização de nitrogênio orgânico e inorgânico. A gama de plantas hospedeiras varia dentro das espécies do gênero Cylindrocarpon. Diferenças entre isolados, quanto a sua virulência, têm sido relatadas em C. destructans (Brayford, 1993).

Em 1966, Booth citado por Brayford (1993) dividiu as espécies do gênero Cylindrocarpon em quatro grupos: Grupo 1 (clamidósporos ausentes e microconídios presentes); Grupo 2 (clamidósporos ausentes e microconídios ausentes); Grupo 3 (clamidósporos presentes e microconídios presentes) e Grupo 4 (clamidósporos presentes e microconídios ausentes). Samuels \& Brayford (1990) discordaram dessa divisão, pelo fato de uma mesma espécie poder se localizar em mais de um grupo. O anamorfo, C. destructans var. destructans, é caracterizado pelo crescimento rápido em meio de cultura e pela formação de clamidósporos discretos, enquanto que, $C$. destructans var. coprosmae tem uma taxa de crescimento lento e não forma clamidósporos.

O objetivo do trabalho foi caracterizar os sintomas da doença e identificar morfologicamente o agente causal do escurecimento do tronco de videiras (pé-preto) na região da Serra Gaúcha, RS.

Videiras da cultivar Bordô, com três anos de idade, apresentando sintomas de escurecimento do tronco, foram coletadas em um vinhedo do Município de Flores da Cunha, RS, em 2000, e, levadas para o Laboratório de Fitopatologia da Embrapa Uva e Vinho, Bento Gonçalves, RS.

Fragmentos de tecido do tronco da planta foram colocados em câmara-úmida durante sete dias, à temperatura ambiente e, após este período, foi realizado o isolamento do fungo Cylindrocarpon sp. em meio de cultura BDA (batatadextrose-ágar), contido em placas de Petri. As colônias foram incubadas em BOD a $20^{\circ} \mathrm{C}$, com luz fluorescente e fotoperíodo de $12 \mathrm{~h}$ durante 15 dias. Isolamentos monospóricos foram realizados a partir dos macroconídios produzidos pelo fungo. Para conservação do isolado, o mesmo foi armazenado em BDA e em papel filtro sob o registro de CNPUV 286.

O teste de patogenicidade foi conduzido em dois ensaios. O primeiro utilizando plantas cultivadas em meio de cultura e o segundo em vasos com solo, em casa de vegetação.

No trigésimo dia, as plantas da cultivar Bordô, in vitro, cultivadas em meio Galzy (Galzy, 1964) foram inoculadas depositando-se três discos de meio de cultura com micélio de Cylindrocarpon sp. no colo de cada planta. As plantas foram incubadas a $24{ }^{\circ} \mathrm{C}$ com fotoperíodo de $12 \mathrm{~h}$. Após 30 dias, avaliou-se à presença de sintomas e reisolamento em meio BDA, para recuperação do isolado inoculado.

Estacas da cultivar Bordô foram plantadas em solo previamente infestado com inóculo (pedaços de ramos de videira autoclavados por 50 min em dois dias consecutivos e inoculados com o isolado de Cylindrocarpon sp., incubado à temperatura ambiente durante 20 dias). Seis meses após, as plantas foram coletadas e avaliadas quanto à presença de sintomas de escurecimento na parte inferior da estaca e apodrecimento de raízes. Amostras de tecido foram retiradas, desinfestadas com álcool 50\% por 20 segundos e $\mathrm{NaOCl}$ 2\% por 2 min, depositadas em BDA contido em placas de Petri, para recuperação do isolado do fungo inoculado.

Colônias do fungo com 15 dias de idade foram utilizadas no trabalho de identificação da espécie. As seguintes características foram avaliadas: colônia (coloração, aspecto e diâmetro); conidióforos (tamanho, presença de ramificações e tipo de fiálides); célula conidiogênica (formato, largura da base, largura do ápice e presença de colarete); conídios (tipo, tamanho, presença de cicatriz, septação, coloração e forma); clamidósporos (presença, coloração e diâmetro). As chaves de identificação para a espécie foram as de Booth (1967), Brayford (1987) e Samuels \& Brayford (1990).

Nos vinhedos, a doença tem sido mais comum em plantas jovens, até cinco anos de idade, caracterizando-se pela redução do vigor e do número de brotações, evoluindo para o murchamento repentino da parte aérea e, conseqüentemente, a morte da planta (Figura 1A). Observou-se na região do colo da planta um completo escurecimento interno, de coloração marrom escura a preta (Figura 1B), diferindo dos sintomas da fusariose da videira, que é restrita a região do xilema. Abaixo da linha do solo, observou-se o escurecimento e apodrecimento do sistema radicular da planta (Figura 1C). Até então, esta doença não havia sido relatada no Brasil, embora não seja difícil efetuar o isolamento deste patógeno em muitos solos, pois o mesmo pode sobreviver longos períodos como saprófita (Booth, 1967).

Os dois métodos utilizados para a avaliação dos Postulados de Koch possibilitaram a recuperação do isolado inoculado e a reprodução dos sintomas típicos da doença. As mudas de videira, cultivadas in vitro, permitiram a avaliação do desenvolvimento de sintomas, em metade do tempo (três meses) necessário para a mesma avaliação em casa de vegetação (seis meses).

O isolado CNPUV 286 apresentou colônia com micélio aéreo, flocoso, escasso (Figura 1D), inicialmente de coloração cinza-esbranquiçada tornando-se marrom-clara após dez dias de incubação sob luz fluorescente, a $20{ }^{\circ} \mathrm{C}$, atingindo aproximadamente $65 \mathrm{~mm}$ de diâmetro (crescimento rápido). Reverso das placas de coloração marrom-avermelhada. Conidióforos cilindráceos, eretos ou ligeiramente flexuosos, com fiálides terminais ou laterais, cilíndricas ou afilando-se em direção ao ápice, medindo 32,5 - 70 x 1,25 $\mu \mathrm{m}$ (ápice) - 2,5 $\mu \mathrm{m}$ (base) e com a presença de colarete. Microconídios hialinos, elípticos a ovalados, medindo 10 - 17,5 x 2,5 - 5,0 $\mu \mathrm{m}$. Macroconídios abundantes, hialinos, cilíndricos a ligeiramente curvos com terminações arredondadas, retas, com um ligeiro estreitamento na base, com cicatriz basal, septado (um a três septos), medindo 20 - 47,5 x 2,5 a 7,5 $\mu \mathrm{m}$ e produzidos em conidióforos terminados em uma ou mais fiálides (Figura 2A, B e C). Verificou-se a presença de clamidósporos amarelos a marrom, formados isoladamente ou em cadeias, globosos a subglobosos medindo 5,0 - 20 × 7,5 - 12,5 $\mu \mathrm{m}$ (Figura 2D). Pelas características morfológicas, concluiu-se que o isolado CNPUV 286, estudado neste trabalho, é C. destructans. As características avaliadas foram similares às encontradas por Samuel \& Brayford (1990), como crescimento da colônia entre 


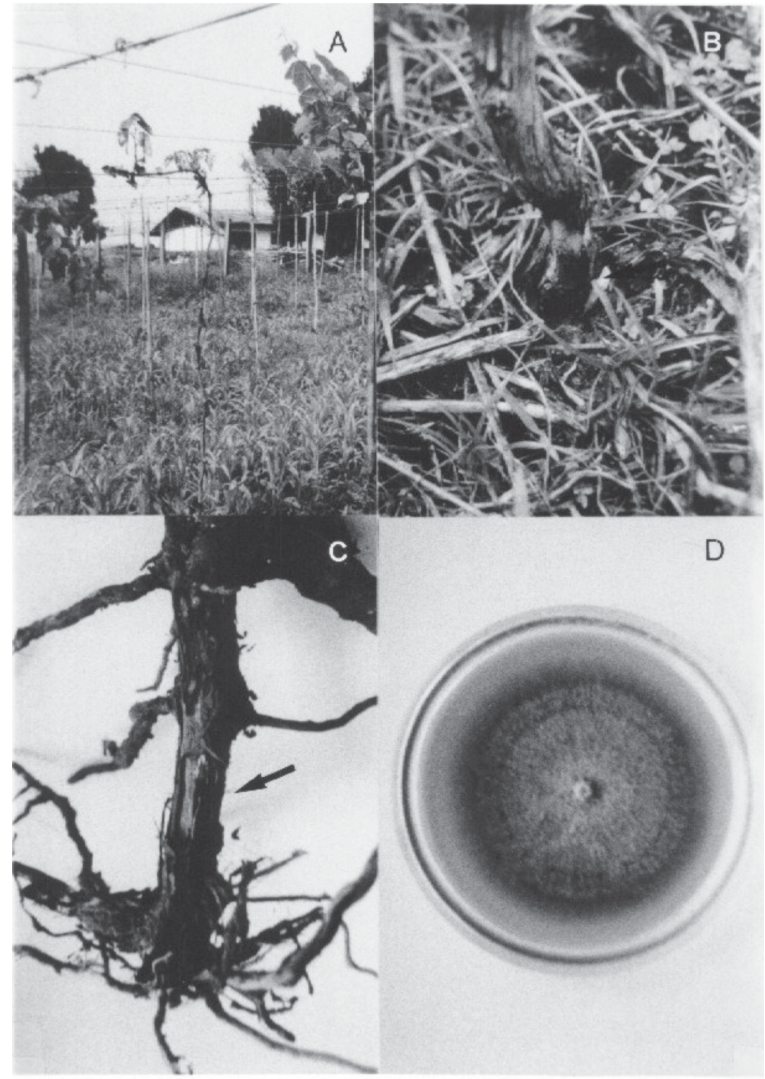

FIG. 1 - Planta de videira (Vitis labrusca) da cv. Bordô apresentando secamento da parte aérea devido a infecção por Cylindrocarpon destructans (A); escurecimento do tronco da planta (seta) (B); apodrecimento de raízes da cv 43-43 (seta) (C) e colônia de C. destructans em BDA (D).

30 a 70 mm após dez dias de incubação; cor e aspecto do micélio; tipos e arranjo das fiálides e tamanho dos microconídios e macroconídios medindo 4 a 13 x 4 - $6 \mu$ m e 25 a 46 x 4,0 a 8,0 $\mu \mathrm{m}$, respectivamente.

Algumas questões sobre a origem, a disseminação, a distribuição e as formas de controle do agente causal do pépreto da videira serão alvo de trabalhos futuros.

\section{REFERÊNCIAS BIBLIOGRÁFICAS}

ARMENGOL, J., VICENT, A., TORNÉ, L., GARCIAFIGUERRES, F. \& GARCIA-JIMÉNEZ, J. Fungi associated with esca and grapevine declines in Spain: a three-year survey. Phytopathologia Mediterranea 40:325-329. 2001.

AUGER, J., ESTERIO, M., CASTILlo, G., DROGUETT, A., VENEGAS, J. \& REVECO, M. Propagación de plantas de vid (Vitis vinifera L.) cv. Red Globe libres de Cylindrocarpon destructans (Zinss.), Scholten. Fitopatologia Brasileira 26:454. 2001. (Resumo)

BOOTH, C. Nectria radicicola. In: CMI Descriptions of pathogenic fungi and bacteria London: Commonwealth Agricultural Bureaux, n.148. 1967.

BRAYFORD, D. Cylindrocarpon. In: Singleton, L.L., Mihail. J.D. \&

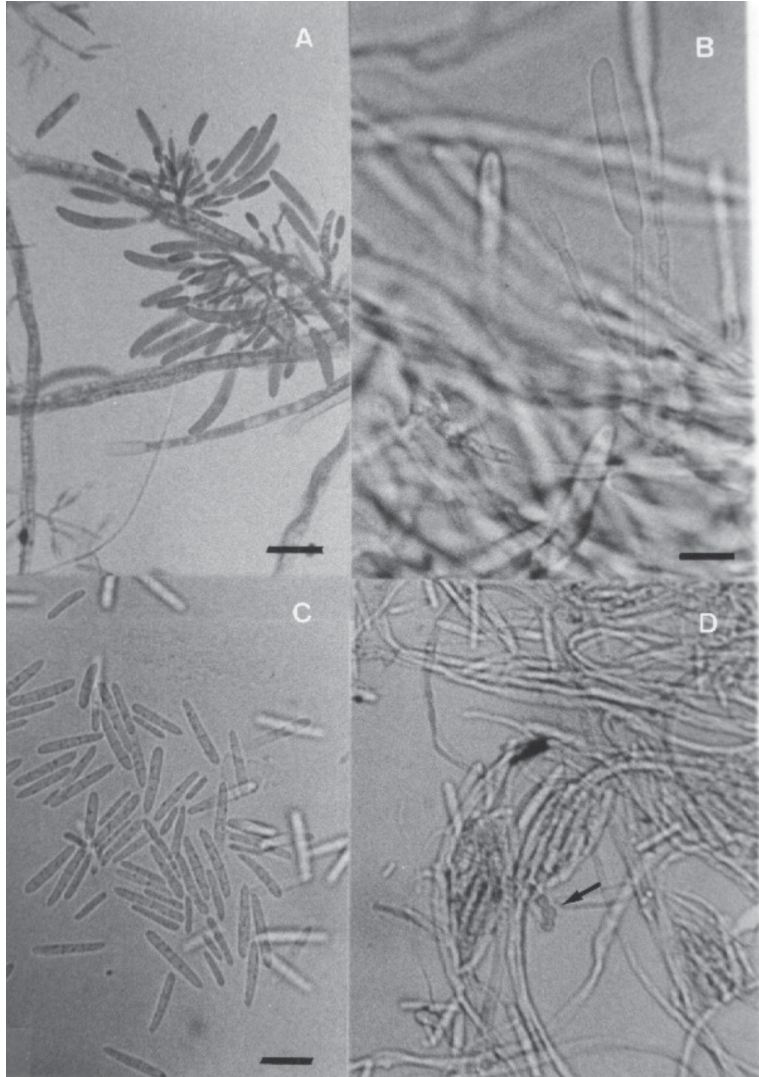

FIG. 2 - Fiálides com macroconídios produzidos por Cylindrocarpon destructans. Barra $30 \mu \mathrm{m}$ (A); Detalhe do macroconídio aderido a fiálide. Barra $12 \mu \mathrm{m}$ (B); formato e septação de macroconídios maduros (C). Micélio e clamidósporos (seta). Barra $30 \mu \mathrm{m}$ (D).

Rush, C.M. (Eds.) Methods for research soilborne phytopatohogenic fungi. St Paul. APS Press. 1993. pp.103-106.

BRAYFORD, D. Cylindrocapon obtusisporum. Mycopathologia 100:129-130. 1987

GALZY, R. Technique de thermothérapie des viroses de la vigne. Annales des. Epiphyties 15:245-256. 1964.

GRASSO, S. \& MAGNANO DI SAN LIO, G. Infezioni di Cylindrocarpon obtusisporum su piante di vite in Sicilia. Vitis 14:3639. 1975.

REGO, C., OliveiRA, H., CARVAlHO, A. \& PHILliPS, A. Involvement of Phaeoacremonium spp. and Cylindrocarpon destructans with grapevine decline in Portugal. Phytopathologia Mediterranea 39:76-79. 2000.

RUMBOS, I. \& RUMBOU, A. Fungi associated with esca and young grapevine decline in Greece. Phytopathologia Mediterranea 40:330335. 2001.

SAMUELS, G.J. \& BRAYFORD, D. Variation in Nectria radicicola and its anamorph, Cylindrocarpon destructans. Mycology Research 94:433-442. 1990.

SCHECK, H.J., VASQUEZ, S.J., FOGLE, D. \& GUBLER, W.D. Grape growers report losses to black-food and grapevine decline. California Agriculture 52:19-23. 1998. 